\title{
Literasi Kesehatan Mental dan Sikap Komunitas sebagai Prediktor Pencarian Pertolongan Formal
}

\author{
Anita Novianty ${ }^{1} \mathcal{E}$ M. Noor Rochman Hadjam ${ }^{2}$ \\ 1,2Fakultas Psikologi Universitas Gadjah Mada Yogyakarta
}

\begin{abstract}
Mental illness had contributed 23\% of global mental health burden. The high number of mental illness prevalence had impact on social and economic burden, yet only $10 \%$ was treated by professional. This study aimed to find out the significance of mental health literacy and community attitude toward mental illness toward formal help seeking. The hypothesis was mental health literacy and community attitude toward mental illness predicted formal help-seeking. A survey method was applied with total respondent was 168 people living in urban area. Multiple regression analysis was used to analyze the data. The result showed mental health literacy and community attitude toward mental illness significantly predicted the formal help seeking simultaneously $(F=3.466 ; p<0.05)$. This study concluded that people who well literate in mental health issues and having positive community attitude in their environment can affect their help seeking to professional treatment.
\end{abstract}

Keywords: community attitude; formal help seeking; mental health literacy

Abstrak. Gangguan mental berkontribusi sebesar 23\% terhadap beban kesehatan mental dunia. Tingginya angka prevalensi gangguan mental berdampak pada beban sosial dan ekonomi, namun hanya $10 \%$ yang menerima penanganan profesional. Penelitian ini bertujuan untuk menemukan signifikansi literasi kesehatan mental dan sikap komunitas terhadap gangguan mental terhadap pencarian pertolongan formal. Hipotesisnya adalah literasi kesehatan mental dan sikap komunitas terhadap gangguan mental memprediksi pencarian pertolongan formal. Metode survei digunakan dengan jumlah responden 168 orang yang tinggal di area perkotaan. Analisis regresi ganda digunakan untuk analisa data. Hasil menunjukkan literasi kesehatan mental dan sikap komunitas terhadap gangguan mental secara bersama-sama signifikan memprediksi pencarian pertolongan formal $(\mathrm{F}=3,466 ; \mathrm{p}<0,05)$. Penelitian ini menyimpulkan bahwa orang yang memiliki literasi kesehatan mental yang tinggi dan sikap komunitas yang positif memengaruhi pencarian pertolongan ke penanganan profesional.

Kata kunci: literasi kesehatan mental; pencarian pertolongan formal; sikap komunitas

Gangguan mental merupakan salah satu tantangan kesehatan global yang memiliki dampak signifikan dikarenakan prevalensi yang tinggi dan penderitaan berat yang

${ }^{1}$ Koresponden untuk tulisan ini ditujukan kepada: anita_novianty@ugm.ac.id ditanggung oleh individu, keluarga, komunitas, dan negara (Kohn, Saxena, Levav, \& Saraceno, 2004). Gangguan mental akan muncul satu waktu pada $10 \%$ populasi orang dewasa (World Health Organization, 2001). Pada tahun 1990, gangguan mental dan neurologis berkontribusi sebesar $10 \%$ dari total Disability- 
Adjusted Life Years (DALYs yaitu tahun yang dihabiskan seseorang dalam kondisi disabilitas), kemudian pada tahun 2000 menjadi sebesar $12 \%$, dan diperkirakan terus akan meningkat hingga $15 \%$ pada tahun 2020 (World Health Organization, 2001). Estimasi saat ini 450 ribu orang setidaknya memiliki satu gangguan mental (McBain, Salhi, Morris, Salomon, \& Betancourt, 2012).

Berdasarkan data Riset Kesehatan Dasar (Riskedas) menunjukkan prevalensi gangguan jiwa berat nasional sebesar 1,7 per mil, yang artinya 1-2 orang dari 1000 penduduk Indonesia mengalami gangguan jiwa (Badan Penelitian dan Pengembangan Kesehatan, 2013). Prevalensi penduduk yang mengalami gangguan mental emosional secara nasional pada tahun 2013 sebesar enam persen (37.728 orang dari subjek yang dianalisis). Angka bunuh diri di Indonesia juga terus meningkat hingga mencapai 1,6 - 1,8 tiap 100.000 penduduk. Adapun kejadian bunuh diri tertinggi berada pada kelompok usia remaja dan dewasa muda (15-24 tahun). Fenomena bunuh diri di Indonesia meningkat pada kelompok masyarakat yang rentan terhadap sumber tekanan psikososial yaitu pengungsi, remaja, dan masyarakat sosial ekonomi rendah (World Health Organization, 2012).

Prevalensi individu dengan gangguan mental secara global sangat tinggi, namun jumlah individu yang mendapatkan penanganan profesional kurang dari $10 \%$ di negara-negara dengan pendapatan menengah ke bawah (McBain et al., 2012). Di banyak konteks negara-negara dengan pendapatan menengah ke bawah, gangguan mental lebih banyak ditangani oleh penyembuh tradisional (Burns, 2014). Penelitian Subandi dan Utami (1996) pada keluarga yang memiliki anggota keluarga dengan gangguan mental menemukan bentuk pencarian pertolongan informal dengan cara pengobatan ke dukun atau ahli agama. Temuan ini didukung oleh Salim (2014) bahwa salah satu bentuk pencarian pertolongan yang dominan terkait gangguan mental baik pada penduduk di desa maupun kota adalah mendatangi kiai. Dampak dari tingginya angka penanganan yang bersifat informal adalah penundaan pencarian pertolongan formal (Burns, 2014; Uwakwe \& Otakpor, 2014) dan juga penundaan diketahuinya gangguan dari onset pertama kali muncul (Kohn et al., 2004).

Pencarian pertolongan formal terkait gangguan mental adalah niat atau upaya proses pengatasan adaptif individu yang berusaha memeroleh pendampingan eksternal yaitu tenaga profesional kesehatan untuk menangani isu terkait gangguan mental. Adapun aspek-aspek dari pencarian pertolongan formal dalam penelitian ini terdiri dari keterbukaan diri, nilai dan kebutuhan, dan keyakinan orang lain terhadap penanganan profesional (Ajzen, 1988; Elhai, Schweinle, \& Anderson, 2008; Fischer \& Turner, 1970; Mak \& Davis, 2013; Rickwood, Thomas, \& Bradford, 2012; Salim, 2014).

Berdasarkan penelitian sebelumnya terdapat beberapa model yang dapat menjelaskan prediktor pencarian pertolongan, walaupun beberapa diantaranya saling kontradiktif. Dearing dan Twaragowski (2012) mengemukakan dua faktor utama yang berkaitan dengan pencarian pertolongan, yaitu faktor terkait individu dan faktor terkait penanganan. Faktor terkait individu yang memengaruhi pencarian pertolongan seperti faktor demografi (Mendoza, Masuda, \& Swartout, 2015; Reynders, Kerkhof, Molenberghs, \& Van Audenhove, 2015), kepribadian dan kompetensi emosional (Mendoza et al., 2015; Umubyeyi, Mogren, 
Ntaganira, \& Krantz, 2016). Faktor terkait penanganan yang memengaruhi keputusan individu untuk mencari pertolongan seperti faktor geografis, transportasi, waktu, dan biaya (Fox, Blank, Rovnyak, \& Barnett, 2001; Sun et al., 2016).

Salah satu faktor yang menghambat pencarian pertolongan formal terkait gangguan mental pada level individu adalah rendahnya pengetahuan mengenai gangguan mental (Andersson et al., 2013; Fox et al., 2001; Sun et al., 2016; Umubyeyi et al., 2016). Rendahnya pengetahuan ditunjukkan dari ketidakmampuan dalam identifikasi gangguan mental (Andersson et al., 2013) atau konsepsi keliru mengenai gangguan mental yang memicu orang cenderung mencari pertolongan informal (Mehta \& Thornicroft, 2014; Umubyeyi et al., 2016).

Literasi kesehatan mental didefinisikan sebagai pengetahuan dan keyakinan mengenai gangguan-gangguan mental yang membantu rekognisi, manajemen, dan prevensi (Jorm, 2000). Aspek-aspek kesehatan mental dalam penelitian ini terdiri dari rekognisi gejala-gejala gangguan mental, pengetahuan mengenai informasi kesehatan mental, pengetahuan mengenai penyebab gangguan mental, pengetahuan mengenai pencarian pertolongan formal, pengetahuan cara menjaga kesehatan mental positif, dan keyakinan mengenai gangguan mental (Jorm, 2000; O'Connor \& Casey, 2015; O'Connor, Casey, \& Clough, 2014; Wang et al., 2013).

Marastuti (2014) menemukan hubungan positif antara literasi kesehatan mental dan perilaku pencarian pertolongan. Literatur sebelumnya juga menunjukkan bahwa literasi kesehatan mental berkaitan dengan intensi dan perilaku pencarian pertolongan (Mason, Hart, Rossetto, \& Jorm, 2015). Literasi kesehatan mental berkaitan dengan keyakinan dan tindakan untuk mencari pertolongan profesional (Jorm, 2000). Keyakinan dan intensi terhadap pencarian pertolongan memengaruhi tindakan nyata pada respon individu untuk mendekati dan merujuk orang dengan gangguan mental pada penanganan yang tepat (Yap \& Jorm, 2012).

Kido, Kawakami, Miyamoto, Chiba dan Tsuchiya (2013) menemukan asosiasi antara sosial kapital pada level individu dan stigma gangguan mental. Secara khusus, rasa percaya dalam komunitas, kerja sama, dan hubungan mutual berkaitan dengan rendahnya stigma. Rasa percaya dalam komunitas berkaitan dengan rasa percaya pada orang dengan gangguan mental yang menyebarkan keyakinan bahwa mereka aman dan tidak melukai orang lain, serta adanya harapan untuk menerima bantuan dari tetangga.

Penelitian yang dilakukan oleh Hickling, Robertson-Hickling, dan Paisley (2011) juga menemukan perubahan sikap individu terhadap gangguan mental dan rendahnya stigma terjadi ketika keterlibatan komunitas dengan orang gangguan mental meningkat. Stigma negatif berubah menjadi positif ketika adanya kebersamaan dan kebaikan hati, serta penempatan layanan kesehatan mental komunitas di sistem layanan kesehatan primer.

Sikap komunitas terhadap gangguan mental didefinisikan sebagai evaluasi subjektif individu sebagai bagian dari komunitas di area tempat tinggalnya terhadap penerimaan atau penolakan terkait kehadiran orang dengan gangguan mental dan fasilitas layanan kesehatan mental di komunitas. Aspek-aspek dari sikap komunitas terhadap gangguan mental terdiri dari keterbukaan pikiran dan pro-integrasi, takut dan penghindaran, dan ideologi kesehatan mental komunitas (Högberg, Magnusson, 
Ewertzon, \& Lützén, 2008; Taylor \& Dear, 1981).

Model Perilakuan yang dikemukakan oleh Andersen (1995) menemukan bahwa faktor predisposisi dan sumber yang memfasilitasi (seperti keluarga atau komunitas) dapat menjadi variabel independen yang memengaruhi penggunaan layanan kesehatan. Cauce et al., (2002) mengemukakan bahwa keputusan pencarian pertolongan bergantung pada rekognisi (terdefinisi secara epidemiologis atau persepsi kebutuhan) dan keputusan pencarian pertolongan (dengan paksaan atau sukarela) yang dipengaruhi oleh konteks terdekat ke individu (keluarga) hingga konteks terjauh dari individu (budaya). Budaya dapat memengaruhi keyakinan awam mengenai penyebab gangguan mental dan referensi orang terkait pencarian pertolongan (Wong, Tran, Kim, Kerne, \& Calfa, 2010). Pola perilaku pencarian pertolongan keluarga dengan gangguan mental menunjukkan bahwa pencarian pertolongan diprediksi dari analisis penyebab dan pengaruh eksternal (Subandi \& Utami, 1996).

Berdasarkan kajian literatur dan penelitian sebelumnya, hipotesis penelitian ini adalah literasi kesehatan mental dan sikap komunitas terhadap gangguan mental secara signifikan memprediksi pencarian pertolongan formal. Tujuan dari penelitian ini adalah menguji signifikansi variabel-variabel prediktor (literasi kesehatan mental dan sikap komunitas terhadap gangguan mental) terhadap pencarian pertolongan formal dan menemukan kontribusi efektif masing-masing variabel.

\section{Metode}

Penelitian ini menggunakan pendekatan kuantitatif dengan desain survei lapangan. Survei lapangan biasanya digunakan untuk mengevaluasi sikap atau perilaku tertentu, serta memprediksi perilaku (Bordens \& Abbott, 1991).

Total subjek yang berpartisipasi dalam penelitian ini sebanyak 168 orang yang tinggal di kawasan perkotaan (kisaran usia 15-63 tahun; 26 laki-laki dan 65 perempuan). Kriteria inklusif terdiri dari: a) Berusia di atas 15 tahun; dan b) Tinggal di area tempat tinggalnya lebih dari dua tahun. Total subjek yang berpartisipasi dalam uji skala sebanyak 77 orang. Total subjek yang berpartisipasi dalam pengumpulan data penelitian sebanyak 91 orang.

Penelitian ini menggunakan tiga instrumen yang dikembangkan penulis dan dimodifikasi dari penelitian sebelumnya. Skala pencarian pertolongan formal dikembangkan penulis berdasarkan pengukuran pencarian pertolongan oleh (Rickwood et al. (2012), Teori Perilaku Terencana oleh Ajzen (1988) dan beberapa penelitian mengenai pengembangan teori dan pengukuran (Elhai et al., 2008; Fischer \& Turner, 1970; Mak \& Davis, 2013; Salim, 2014). Skala ini mengukur niat atau usaha individu dalam mencari bantuan eksternal oleh profesional. Format skala ini adalah Likert dengan empat alternatif jawaban (sangat tidak setuju, tidak setuju, setuju, sangat setuju). Jumlah aitem yang digunakan dalam penelitian adalah delapan aitem dengan nilai reliabilitas sebesar 0,740 .

Skala literasi kesehatan mental dikembangkan oleh peneliti berdasarkan kerangka konseptual dari literatur sebelumnya (Jorm, 2000; O'Connor \& Casey, 2015; O'Connor et al., 2014; Wang et al., 2013). Skala ini mengukur rekognisi publik, pengetahuan, dan keyakinan mengenai gangguan mental. Format skala ini adalah dikotomi. Jumlah aitem yang digunakan dalam penelitian adalah 11 
aitem dengan nilai reliabilitas sebesar 0,760 .

Skala sikap komunitas terhadap gangguan mental diadaptasi dari Skala Community Attitude toward Mental Illness (CAMI) yang dikembangkan oleh Högberg et al. (2008), yang kemudian di beberapa aitem dimodifikasi sesuai konteks subjek penelitian. Skala ini mengukur evaluasi subjektif individu sebagai bagian dari komunitas terhadap penerimaan atau penolakan terhadap kehadiran orang dengan gangguan mental dan fasilitas layanan kesehatan mental di area tempat tinggal mereka. Format skala ini adalah Likert dengan empat alternatif jawaban (Sangat tidak setuju, tidak setuju, setuju dan sangat setuju). Total aitem yang digunakan dalam penelitian ini adalah tujuh aitem, dengan nilai reliabilitas 0,753.

Data dianalisis dengan analisis regresi ganda dengan perangkat lunak statistik. Uji asumsi yang digunakan dalam penelitian ini adalah normalitas, liniearitas, dan multikoliniearitas.

\section{Hasil}

Pengambilan data penelitian dilakukan pada tanggal 22 - 28 Mei 2016 di RT 04, RT 05 dan RT 06. Total responden pada tahap pengambilan data ini sebanyak 100 orang, namun data yang dapat dianalisis sebanyak 91 orang. Hasil analisis pada sampel penelitian menunjukkan deskripsi statistik sebagai berikut:

\section{Deskripsi hasil data penelitian}

Deskripsi data disajikan dalam rerata hipotesis dan rerata empirik yang diperoleh dari respon jawaban subjek terhadap setiap skala yang diberikan. Deskripsi data penelitian dapat dilihat pada Tabel 1.

Berdasarkan analisis deskriptif empirik untuk data pencarian pertolongan formal didapatkan skor maksimum sebesar 25 dan skor minimum sebesar 15. Berdasarkan skor rerata menunjukkan bahwa rerata empirik $(\bar{x}=21,01)$ lebih tinggi dari rerata hipotetik $(\mu=20)$ yang menunjukkan bahwa pencarian pertolongan formal subjek penelitian cukup tinggi.

Hasil perbandingan standar deviasi menunjukkan bahwa standar deviasi empirik $(\sigma=2,019)$ lebih rendah daripada standar deviasi hipotetik $(\sigma=4)$. Hal ini menunjukkan bahwa pencarian pertolongan formal subjek penelitian memiliki variasi yang rendah, dengan kata lain pencarian pertolongan formal antara subjek satu dan lainnya memiliki kemiripan atau seragam.

Tabel 1

Rerata hipotetik dan rerata empiris

\begin{tabular}{|c|c|c|c|c|c|c|c|c|}
\hline \multirow{2}{*}{ Variabel } & \multicolumn{4}{|c|}{ Rerata Hipotetik } & \multicolumn{4}{|c|}{ Rerata Empirik } \\
\hline & $\operatorname{Max}$ & Min & $\mu$ & $\sigma$ & Max & Min & $\bar{x}$ & $\bar{\sigma}$ \\
\hline Pencarian Pertolongan Formal & 32 & 8 & 20 & 4 & 25 & 15 & 21,01 & 2,019 \\
\hline Literasi Kesehatan Mental & 11 & 0 & 5,5 & 1,83 & 11 & 0 & 6,98 & 2,481 \\
\hline $\begin{array}{l}\text { Sikap Komunitas terhadap } \\
\text { Gangguan Mental }\end{array}$ & 28 & 7 & 17,5 & 3,5 & 23 & 13 & 18,21 & 1,847 \\
\hline
\end{tabular}

Keterangan: Max = skor maksimum; Min = skor minimum; $\mu=$ rerata hipotetik; $\bar{x}=$ rerata empirik; $\sigma=$ standar deviasi. 
Berdasarkan analisis deskriptif empirik untuk data literasi kesehatan mental didapatkan skor maksimal sebesar 11 dan skor minimal sebesar 0. Berdasarkan skor rerata menunjukkan bahwa rerata empirik $(\bar{x}=6,98)$ lebih tinggi dari rerata hipotetik $(\mu=5,5)$ yang menunjukkan bahwa literasi kesehatan mental subjek penelitian tinggi. Hasil perbandingan standar deviasi menunjukkan bahwa standar deviasi empirik $(\sigma=2,481)$ lebih tinggi daripada standar deviasi hipotetik $(\sigma=1,83)$. Hal ini menunjukkan bahwa literasi kesehatan mental subjek penelitian memiliki variasi yang tinggi.

Berdasarkan analisis deskriptif empirik untuk data sikap komunitas terhadap gangguan mental didapatkan skor maksimal sebesar 23 dan skor minimal sebesar 13. Berdasarkan skor rerata menunjukkan bahwa rerata empirik $(\bar{x}=18,21)$ lebih tinggi dari rerata hipotetik $(\mu=17,5)$ yang menunjukkan bahwa sikap komunitas dari subjek penelitian positif.Hasil perbandingan standar deviasi menunjukkan bahwa standar deviasi empirik $(\sigma=1,847)$ lebih rendah daripada standar deviasi hipotetik $(\sigma=3,5)$. Hal ini menunjukkan bahwa sikap komunitas subjek penelitian memiliki variasi yang rendah.

\section{Uji hipotesis}

Uji hipotesis dilakukan dengan analisis regresi ganda. Hasil analisis regresi menghasilkan nilai $\mathrm{F}=3,466(\mathrm{p}<0,05)$. Hasil ini mengindikasikan bahwa variabel literasi kesehatan mental dan sikap komunitas terhadap gangguan mental secara bersama-sama memengaruhi pencarian pertolongan formal. Sumbangan efektif yang diberikan kedua variabel prediktor (literasi kesehatan mental dan sikap komunitas terhadap gangguan mental) terhadap variabel kriterium (pencarian pertolongan formal) sebesar tujuh persen.
Berdasarkan analisis tersebut, maka dapat disimpulkan bahwa hipotesis penelitian diterima.

Hasil analisis regresi dengan metode Stepwise menunjukkan bahwa variabel sikap komunitas terhadap gangguan mental lebih kuat dalam memprediksi intensi pencarian pertolongan formal $(\mathrm{F}=5,473 ; \mathrm{p}<0,05)$. Akan tetapi, variabel literasi kesehatan mental tidak dapat memprediksi intensi pencarian pertolongan formal secara independen $(\mathrm{F}=0,176$; $\mathrm{p}>0,05)$.

\section{Diskusi}

Hasil dari kajian pustaka menunjukkan bahwa literasi kesehatan mental berkaitan dengan perilaku pencarian pertolongan formal (Hanisch et al., 2016; Marastuti, 2014; Mason et al., 2015; Wilson, Bushnell, \& Caputi, 2011; Yap \& Jorm, 2012). Selain itu, sikap komunitas terhadap gangguan mental juga memengaruhi niat atau upaya seseorang dalam mencari pertolongan (Ayazi, Lien, Eide, Shadar, \& Hauff, 2014; Hickling, Robertson-Hickling, \& Paisley, 2011; Kido et al., 2013). Hasil analisis statistik dalam penelitian ini menunjukkan bahwa literasi kesehatan mental dan sikap komunitas terhadap gangguan mental secara bersama-sama berperan dalam pencarian pertolongan formal $(\mathrm{F}=3,466$; $\mathrm{p}<0,05)$. Hal ini mengindikasikan apa yang diketahui individu dan apa yang berterima di masyarakat memengaruhi pencarian pertolongan formal. Hasil penelitian ini mendukung literatur sebelumnya bahwa pemilihan layanan untuk pencarian pertolongan tergantung dari pengenalan masalah (baik yang terdefinisi secara epidemiologis atau analisis penyebab) dan pengaruh konteks yang paling dekat dengan individu yaitu 
keluarga hingga pada budaya (Cauce et al., 2002; Subandi \& Utami, 1996).

Temuan yang berbeda dari hasil penelitian sebelumnya ditunjukkan dari analisis terpisah pada masing-masing variabel prediktor. Hasil analisis regresi secara independen menunjukkan variabel sikap komunitas terhadap gangguan mental dapat secara signifikan memprediksi pencarian pertolongan formal $(\mathrm{F}=5,473$; $\mathrm{p}<0,05)$ dibandingkan literasi kesehatan mental. Variabel literasi kesehatan mental secara independen tidak dapat memprediksi pencarian pertolongan formal secara signifikan ( $F=0,176 ; p>0,05)$.

Peran sikap komunitas terhadap pencarian pertolongan formal

Rickwood, Deane, Wilson, dan Ciarrochi (2005) menyebutkan bahwa pencarian pertolongan erat kaitannya dengan pengaruh sosial yaitu dukungan keluarga dan teman yang sangat memengaruhi intensi individu mencari pertolongan. Faktor sosial akan memengaruhi determinasi individu dalam memanfaatkan layanan kesehatan (Andersen \& Newman, 1973). Penelitian Salim (2014) terkait intensi pencarian pertolongan pada gangguan mental menemukan bahwa keyakinan normatif lebih berpengaruh daripada kebutuhan dan kontrol perilaku. Hal ini mendukung temuan penelitian bahwa sikap komunitas terhadap gangguan mental memengaruhi pencarian pertolongan formal.

Analisis kategorisasi pada variabel sikap komunitas terhadap gangguan mental menunjukkan bahwa kebanyakan subjek berada pada kategori sedang $(94,5 \%)$, sehingga dapat diartikan sikap komunitas terhadap gangguan mental cukup positif. Hasil kategorisasi ini menunjukkan dua kemungkinan penjelasan yang didukung oleh penelitian sebelumnya. Pertama, adanya keterkaitan antara karakteristik demografi dengan banyaknya subjek penelitian yang berada pada kategorisasi sedang dalam pencarian pertolongan formal. Karakteristik demografi subjek pada penelitian ini menunjukkan bahwa kebanyakan dari mereka memiliki latar pendidikan rendah, tidak bekerja, dan belum memiliki penghasilan sendiri. Keluarga dengan status sosial ekonomi menengah ke bawah yang memiliki anggota keluarga dengan gangguan mental cenderung merujuk pada pencarian pertolongan profesional dibandingkan keluarga dengan pendapatan di atas rata-rata yang cenderung menutupi karena malu (Ojeda \& Bergstresser, 2008; Putri et al., 2013).

Selain itu, kemungkinan kedua yang terjadi biasanya pencarian pertolongan formal didapatkan setelah mencoba mencari pertolongan informal (berbicara pada keluarga/teman dekat atau mendatangi ahli agama) sebelumnya. Penelitian di Afrika, Arab, Asia dan India menunjukkan bahwa individu mencari pertolongan informal terlebih dahulu sebelum mencoba jalur medis (Angermeyer, Breier, Dietrich, Kenzine, \& Matschinger, 2005; Ediriweera, Fernando, \& Pai, 2012; Uwakwe \& Otakpor, 2014). Hal ini juga didukung oleh penelitian Subandi dan Utami (1996) bahwa keluarga dengan gangguan mental biasanya mencari bentuk pertolongan ke dukun atau ahli agama. Bahkan Salim (2014) menyebutkan tidak ada perbedaan bentuk pencarian pertolongan antara masyarakat yang tinggal di desa dan di kota, kebanyakan bentuk pencarian pertolongan untuk gangguan mental adalah dengan cara mendatangi kiai (ahli agama).

Berdasarkan amatan penulis pada saat subjek penelitian merespon aitem-aitem uji coba skala terdapat suatu bentuk 
keyakinan bahwa gangguan mental berbeda dengan gangguan fisik, sehingga perlu penanganan eksklusif. Gangguan mental dipersepsikan sebagai gangguan yang dapat membahayakan orang lain dan mengamuk tanpa dapat diprediksi. Bagi orang dengan gangguan mental yang keluar dari rumah sakit ada anggapan bahwa mereka sudah sembuh dan dapat diterima kembali di masyarakat, namun tidak serta merta dapat membangun relasi sosial dan membina hubungan dengan warga lain. Mereka tetap dianggap berbeda, walaupun juga tidak disingkirkan.

\section{Peran literasi kesehatan mental terhadap} pencarian pertolongan formal

Hasil analisis statistik menunjukkan bahwa variabel literasi kesehatan mental secara independen tidak signifikan berperan terhadap pencarian pertolongan formal. Berdasarkan sudut pandang filosofis, pengetahuan secara konvensional diartikan sebagai keyakinan yang benar adanya dan terjustifikasi. Pendefinisian tersebut dikritik oleh Hunt (2003) bahwa hanya dengan dua komponen esensial itu saja tidak cukup untuk membuat suatu pengetahuan digunakan dalam menentukan kecenderungan suatu perilaku atau yang diistilahkannya sebagai 'usable knowledge'. Komponen ketiga yang diperlukan agar suatu pengetahuan digunakan sebagai kapasitas untuk bertindak sebagaimana fungsinya untuk membuat konsep tujuan, antisipasi dan persepsi adalah keyakinan seseorang terhadap apa yang benar.

Apabila hasil penelitian ini dikaitkan dengan konsep pengetahuan yang diargumentasikan oleh Hunt (2003), maka dapat diindikasikan bahwa kebanyakan partisipan dalam penelitian ini menggunakan 'usable belief' sebagai referensi dalam menentukan kecenderungan tindakan. Hal ini dapat diartikan bahwa apa yang dipercayai sebagai kebenaran oleh partisipan lebih kuat memengaruhi kecenderungan perilakunya daripada pengetahuan yang sifatnya telah terjustifikasi terkait isu gangguan mental.

Penelitian Wong et al. (2010) mengemukakan model pencarian pertolongan profesional yang dipengaruhi oleh keyakinan awam mengenai gangguan mental dan enkulturasi nilai-nilai orang Asia. Konsepsi budaya dan persepsi masyarakat umum mengenai gangguan mental memiliki konsekuensi negatif pada usaha pencarian pertolongan (Link, Phelan, Bresnahan, Stueve, \& Pescosolido, 1999). Pada model yang dikembangkan oleh Altweck, Marshall, Ferenczi, \& Lefringhausen (2015) pun menunjukkan budaya sebagai moderator akan keyakinan pencarian pertolongan profesional. Dalam model tersebut pencarian pertolongan profesional dapat bermula dari telah adanya pengenalan mengenai gangguan mental dari individu atau keyakinan pencarian pertolongan informal.

Apabila ditinjau dari aspek literasi kesehatan mental yang dikonsepsikan para peneliti sebelumnya yang menekankan aspek pengenalan dan pengetahuan, maka pada aspek pengenalan subjek penelitian berbeda dengan masyarakat belahan dunia barat. Kemampuan pelabelan yang tepat pun masih sangat minim. Penelitian sebelumnya menyebutkan bahwa pelabelan terhadap gangguan mental berkaitan dengan identifikasi kebutuhan pencarian pertolongan dari tenaga profesional (Lauber, Nordt, Falcato, \& Rössler, 2004; Wright, Jorm, \& Mackinnon, 2011).

Pengenalan yang tepat terkait gangguan mental berhubungan dengan kecenderungan pemilihan strategi pengatasan masalah kepada tenaga profesional. Pengenalan akan masalah tidak akan 
terlepas dari budaya dan konteks setempat, misalnya individu dengan etnis Asia cenderung untuk tidak mengakui adanya gangguan mental yang nantinya akan memengaruhi keputusan untuk mencari pertolongan dan tipe pertolongan yang dipilih (Cauce et al., 2002).

Literasi kesehatan mental adalah suatu bentuk konsep dalam agenda kesehatan mental global yang bertujuan memberikan pemahaman pada masyarakat umum mengenai isu gangguan mental dan meningkatkan akses dan rujukan pada penanganan yang tepat. Konsep ini dirangkai dalam bentuk pelabelan psikiatris, namun kenyataannya di lapangan ada berbagai macam bentuk pemahaman lokal dalam memahami konsep gangguan mental, serta bentuk pencarian pertolongan, strategi pengatasan masalah dan intervensi yang telah terbangun di masyarakat tertentu.

Kirmayer dan Pedersen (2014) mengemukakan bahwa memberikan edukasi pada pekerja sosial dan masyarakat umum berdasarkan konsep literasi kesehatan mental yang dijadikan standar sama dengan mengabaikan pemahaman lokal serta strategi pengatasan masalah, cara penyembuhan, dukungan sosial, dan reintegrasi yang mungkin telah ada sebelumnya di masyarakat, belum tentu cocok untuk konteks tertentu. Maka dari itu, perlu ada dialog dua arah antara para ahli kesehatan mental dan tokoh/warga masyarakat dengan mempertimbangkan pengetahuan yang bersifat lokal, nilai-nilai dan sudut pandang dari masyarakat itu sendiri (Kirmayer \& Pedersen, 2014).

Peran literasi kesehatan mental dan sikap komunitas terhadap pencarian pertolongan terkait gangguan mental

Pengetahuan mengenai gangguan mental akan mendorong seseorang mencari pertolongan dari tenaga formal dibandingkan informal (Kutcher, Wei, \& Coniglio, 2016). Namun yang terlihat pada subjek penelitian adalah apa yang diyakini benar lebih berpengaruh pada pencarian pertolongan. Keyakinan akan penyebab gangguan mental memengaruhi bentuk pencarian pertolongan individu (Altweck et al., 2015; Subandi \& Utami, 1996; Wong et al., 2010; Wright et al., 2011). Penelitian Subandi (2012) menunjukkan bahwa secara umum pasien gangguan mental akan beralih ke hal-hal yang berkaitan dengan agama dalam mencari pertolongan, karena agama diyakini memberikan dukungan dalam mengatasi tekanan dan gangguan mental yang dialami.

Hasil analisis kategorisasi menunjukkan bahwa pada umumnya literasi kesehatan mental subjek penelitian berada dalam kategori sedang dan tinggi dengan variasi yang sangat beragam. Hasil ini menunjukkan bahwa pemahaman subjek penelitian mengenai gangguan mental tidak serta merta secara langsung memengaruhi pencarian pertolongan formal seseorang. Namun ketika berinteraksi dengan sikap komunitas terhadap gangguan mental, maka secara bersama-sama kedua variabel ini dapat memprediksi pencarian pertolongan formal individu.

Selain itu yang menjadi perhatian lain dalam temuan penelitian ini bahwa kedua variabel prediktor memberikan sumbangan efektif sebesar tujuh persen. Berdasarkan kajian literatur yang telah dilakukan faktor-faktor yang memengaruhi pencarian pertolongan sangat beragam, berbeda dalam tiap konteks dan juga cukup meluas. Kedua variabel prediktor yang diuji dalam penelitian ini hanya sebagian kecil dari faktor-faktor lainnya, salah satunya hambatan eksternal yang sering terjadi di lapangan yaitu faktor geografis, akses transportasi, dan faktor ekonomi 
(Harvey \& Gumport, 2015), serta kemampuan identifikasi tenaga kesehatan terkait kesehatan mental (Marastuti, 2014).

Perlunya pertimbangan literasi kesehatan mental dan sikap komunitas dalam menentukan pencarian pertolongan terkait gangguan mental juga dapat dikaji dari sistem pemaknaan budaya terhadap konsep sakit dan sehat berdasarkan susunan skema budaya dan realitas klinis subjek penelitian. Castillo (1997) mengungkapkan bahwa adanya perbedaan konstruksi kognitif mengenai perilaku normal dan abnormal pada pasien dan kalangan formal (dokter, psikiater, psikolog) atau semi-formal (kyai, dukun, herbalis) akan menentukan realita klinis yang dipahami dan diyakini masing-masing pihak. Hal ini dikarenakan dari sudut pandang pasien, sakit adalah pengalaman subjektif yang dirasakan secara personal, sementara dari sudut pandang kalangan semi-formal/ formal dilihat sebagai diagnosa klinis (Castillo, 1997). Hal ini terkadang menyebabkan adanya perbedaan pendefinisian masalah dari apa yang dialami pasien dan apa yang didefinisikan oleh kalangan formal/semi-formal.

\section{Keterbatasan penelitian}

Keterbatasan penelitian ini meliputi tiga hal yaitu karakteristik demografi subjek penelitian, dinamika masyarakat di area penelitian, dan proses pengambilan data. Pada poin pertama terkait karakterisik demografi, subjek penelitian yang bersedia dan dapat dijangkau saat pengambilan data ini sebagian besar adalah ibu rumah tangga yang tidak bekerja dengan latar pendidikan rendah sehingga kemampuan dan motivasi membaca sangat rendah. Selain itu perlu ada dukungan dan rasa aman dari orang lain agar mereka bersedia menjadi subjek penelitian ini. Apabila mereka tidak dapat memahami aitem, maka cenderung ingin menghentikan pengisian skala atau bertanya pada orang yang dikenalnya.

Poin kedua terkait dinamika masyarakat, yaitu subjek penelitian adalah warga yang tinggal di kawasan padat penduduk di atas tanah sengketa, sehingga ada kecenderungan curiga dengan orang asing yang masuk kawasan mereka. Hal ini dapat diminimalisir dengan mengajak salah satu Ibu PKK (Pembinaan Kesejahteraan Keluarga) sebagai asisten peneliti di lapangan yang menemani penulis selama berada di lapangan.

Poin ketiga adalah proses pengambilan data. Penulis dan asisten peneliti lapangan mendatangi rumah warga satu per satu. Selain keterbatasan pengenalan warga terkait model Likert yang asing sehingga perlu diberi instruksi sederhana dan jelas. Di setiap aitem warga cenderung banyak bercerita mengenai apa yang mereka persepsikan mengenai pernyataan aitem dibandingkan memberikan pilihan jawaban secara langsung. Namun proses ini justru menambah kekayaan data penulis mengenai dinamika di lapangan.

\section{Kesimpulan}

Berdasarkan hasil analisis dan pembahasan dalam penelitian ini maka dapat disimpulkan bahwa pencarian pertolongan formal terkait gangguan mental dipengaruhi secara signifikan oleh literasi kesehatan mental dan sikap komunitas terhadap gangguan mental. Sumbangan efektif literasi kesehatan mental dan sikap komunitas terkait gangguan mental secara bersama-sama terhadap pencarian pertolongan formal sebesar tujuh persen.

Adapun variabel sikap komunitas terhadap gangguan mental lebih kuat dalam memprediksi pencarian 
pertolongan formal dibandingkan variabel literasi kesehatan mental.

\section{Saran}

Berdasarkan hasil amatan penulis di lapangan dan analisis data penelitian, maka diajukan beberapa saran dan usulan yang sebaiknya dilakukan pada penelitian selanjutnya. Kriteria demografi subjek dalam penelitian ini hampir seragam, yaitu sebagian besar adalah perempuan, ibu rumah tangga, tingkat sosial ekonomi menengah ke bawah, dan tidak memiliki pengalaman dengan orang atau anggota keluarga dengan gangguan mental. Penelitian selanjutnya perlu mempertimbangkan keragaman faktor demografi (faktor statis) untuk dapat menemukan apakah ada hubungan langsung atau tidak langsung dalam pencarian pertolongan formal.

Penelitian selanjutnya juga perlu mempertimbangkan situasi subjek penelitian saat pengambilan data berlangsung. Subjek penelitian yang tinggal di kawasan kolektif dapat memiliki respon jawaban yang berbeda ketika mereka sendiri, bersama keluarga atau saat berkumpul dengan tetangga. Apabila ada orang lain di sekitar subjek penelitian, mereka cenderung akan menyamakan jawaban. Hal ini menarik dikaji lebih lanjut oleh peneliti selanjutnya bagaimana pengaruh lingkungan tidak hanya berupa orang signifikan, akan tetapi juga mungkin dalam bentuk pola interaksi atau relasi antar individu maupun kelompok.

Dalam proses uji coba skala, penulis juga mencatat respon warga terhadap aitem dan situasi pengambilan data yang sangat bermanfaat dalam perbaikan aitem dan pembahasan dari hasil analisis statistik. Hadirnya warga setempat (kader PKK) sebagai asisten peneliti memudahkan proses pendekatan ke warga dan penerimaan kehadiran penulis serta kemauan terlibat dalam penelitian. Maka dari itu, penulis menyarankan peneliti selanjutnya melakukan proses yang sama ketika mengambil data di lapangan.

Saran bagi tenaga profesional kesehatan mental, program peningkatan pengenalan dan layanan kesehatan mental di negara-negara maju banyak yang menyasar pada anak-anak maupun remaja di sekolah. Apabila program serupa akan diadaptasi, maka penulis menyarankan bahwa sasaran modul tidak hanya pada target individual dalam kelompok dengan latar tertentu, akan tetapi juga menyasar komunitas di tempat individu tersebut tinggal. Hal ini dikarenakan adanya keterkaitan antara literasi kesehatan mental dan sikap komunitas terhadap pencarian pertolongan formal.

Saran bagi pemangku kepentingan di bidang kesehatan, tingginya prevalensi gangguan mental secara global, menarik perhatian para pengambil kebijakan untuk memerhatikan peningkatan layanan kesehatan mental, terutama di aras primer. Fokus pada peningkatan literasi kesehatan mental pada level individu saja tanpa memperhatikan sikap dan keyakinan yang selama ini ada di masyarakat tidak akan memberikan dampak yang signifikan pada peningkatan penggunaan layanan kesehatan mental.

Studi mengenai gangguan mental tidak dapat terlepas dari produk tradisi intelektual budaya di mana seseorang hidup dan berkembang. Pemahaman mengenai gangguan mental dari pendekatan biomedis saja tidak akan dapat diterima langsung di masyarakat yang selama ini memiliki kepercayaan dan pemahaman lokalnya sendiri. Maka dari itu, pemberdayaan kader sehat mental di masyarakat adalah strategi yang baik, namun bukan hanya mengadaptasi secara 
langsung apa yang diterjemahkan dari perspektif biomedis di negara maju ke masyarakat umum. Penulis menyarankan agar program utama bertujuan untuk peningkatan kesadaran mengenai sehat mental dengan memfasilitasi transformasi simbol atau skema budaya yang ada di masyarakat.

\section{Kepustakaan}

Ajzen, I. (1988). Attitudes, personality, and behavior. England: Open University Press.

Altweck, L., Marshall, T. C., Ferenczi, N., \& Lefringhausen, K. (2015). Mental health literacy: A cross-cultural approach to knowledge and beliefs about depression, schizophrenia and generalized anxiety disorder. Frontiers in Psychology, 6, 1-12. doi: 10.3389/ fpsyg.2015.01272

Andersen, R. (1995). Revisiting the behavioral model and access to medical care: Does it matter? Journal of Health and Social Behavior, 36(1), 1-10.

Andersen, R., \& Newman, J. F. (1973). Societal and individual determinants of medical care utilization in the United States. Health and Society, 51(1), 95. doi: $10.2307 / 3349613$

Andersson, L. M. C., Schierenbeck, I., Strumpher, J., Krantz, G., Topper, K., Backman, G., ... Van Rooyen, D. (2013). Help-seeking behaviour, barriers to care and experiences of care among persons with depression in Eastern Cape, South Africa. Journal of Affective Disorders, 151(2), 439-448. doi: 10.1016/j.jad.2013.06.022

Angermeyer, M. C., Breier, P., Dietrich, S., Kenzine, D., \& Matschinger, H. (2005). Public attitudes toward psychiatric treatment: An international com- parison. Social Psychiatry and Psychiatric Epidemiology, 40(11), 855864. doi: 10.1007/s00127-005-0958-x

Ayazi, T., Lien, L., Eide, A., Shadar, E. J. S., \& Hauff, E. (2014). Community attitudes and social distance towards the mentally ill in South Sudan: A survey from a post-conflict setting with no mental health services. Social Psychiatry and Psychiatric Epidemiology, 49(5), 771-780. doi: 10.1007/s00127013-0775-y

Badan Penelitian dan Pengembangan Kesehatan. (2013). Riset Kesehatan Dasar (RISKESDAS) 2013. (Laporan Penelitian Tidak Dipublikasikan), Kementerian Kesehatan, Jakarta.

Bordens, K. S., \& Abbott, B. B. (1991). Research design and methods. California: Mayfield Publishing Company.

Burns, J. K. (2014). The burden of untreated mental disorders in KwaZulu-Natal Province - mapping the treatment gap. South African Journal of Psychiatry, 20(1), 6-10. doi: 10.7196/sajp.499

Castillo, R. J. (1997). Culture \& mental illness: A client-centered approach. Ontario: Brooks/Cole Publishing Company.

Cauce, A. M., Domenech-Rodríguez, M., Paradise, M., Cochran, B. N., Shea, J. M., Srebnik, D., \& Baydar, N. (2002). Cultural and contextual influences in mental health help seeking: A focus on ethnic minority youth. Journal of Consulting and Clinical Psychology, 70(1), 44-55. doi: 10.1037/0022006X.70.1.44

Dearing, R. L., \& Twaragowski, C. (2010). The social psychology of help seeking. Dalam J. E. Maddux \& J. P. Tangney (Eds), Social psychological foundations of clinical psychology (hlm. 395-415). New York: The Guilford Press. 
Ediriweera, H. W., Fernando, S. M., \& Pai, N. B. (2012). Mental health literacy survey among Sri Lankan carers of patients with schizophrenia and depression. Asian Journal of Psychiatry, 5(3), 246-250. doi: 10.1016/ j.ajp. 2012.02.016

Elhai, J. D., Schweinle, W., \& Anderson, S. M. (2008). Reliability and validity of the attitudes toward seeking professional psychological help scaleshort form. Psychiatry Research, 159(3), 320-329. doi: 10.1016/j.psychres. 2007. 04.020

Fischer, E. H., \& Turner, J. L. (1970). Orientations to seeking professional help:Development and research utility of an attitude scale. Journal of Consulting and Clinical Psychology, 35(1), 79-90.

Fox, J. C., Blank, M., Rovnyak, V. G., \& Barnett, R. Y. (2001). Barriers to help seeking for mental disorders in a rural impoverished population. Community Mental Health Journal, 37(5), 421-436. doi: 10.1023/A:1017580013197

Hanisch, S. E., Twomey, C. D., Szeto, A. C. H., Birner, U. W., Nowak, D., \& Sabariego, C. (2016). The effectiveness of interventions targeting the stigma of mental illness at the workplace: a systematic review. BMC Psychiatry, 16(1), 1-11. doi: 10.1186/s12888-0150706-4

Harvey, A. G., \& Gumport, N. B. (2015). Evidence-based psychological treatments for mental disorders: Modifiable barriers to access and possible solutions. Behaviour Research and Therapy, 68, 1-12. doi: 10.1016/ j.brat.2015.02.004

Hickling, F. W., Robertson-Hickling, H., \& Paisley, V. (2011). Deinstitutionalization and attitudes toward mental illness in Jamaica: A qualitative study. Revista Panamericana de Salud Publica = Pan American Journal of Public Health, 29(3), 169-176. doi: 10.1590/S102049892011000300004

Högberg, T., Magnusson, A., Ewertzon, M., \& Lützén, K. (2008). Attitudes towards mental illness in Sweden: Adaptation and development of the community attitudes towards mental illness questionnaire. International Journal of Mental Health Nursing, 17(5), 302-310. doi: 10.1111/j.1447-0349.2008. 00552.x

Hunt, D. P. (2003). The concept of knowledge and how to measure it. Journal of Intellectual Capital, 4(1), 100113. doi: $10.1108 / 14691930310455414$

Jorm, A. F. (2000). Mental health literacy. Public knowledge and beliefs about mental disorders. The British Journal of Psychiatry, 177(5), 396-401. doi: 10. 1192/bjp.177.5.396

Kido, Y., Kawakami, N., Miyamoto, Y., Chiba, R., \& Tsuchiya, M. (2013). Social capital and stigma toward people with mental illness in Tokyo, Japan. Community Mental Health Journal, 49(2), 243-247. doi: 10.1007/ s10597-012-9548-4

Kirmayer, L. J., \& Pedersen, D. (2014). Toward a new architecture for global mental health. Transcultural Psychiatry, 51(6), 759-776. doi: 10.1177/ 13634615 14557202

Kohn, R., Saxena, S., Levav, I., \& Saraceno, B. (2004). The treatment gap in mental health care. Bulletin of the World Health Organization, 82(11), 858-866. doi: 10 042-96862004001100011

Kutcher, S., Wei, Y., \& Coniglio, C. (2016). Mental health literacy: Past, present, and future. The Canadian Journal of Psychiatry, 61(3), 154-158. doi: 10.1177/ 


\section{9}

Lauber, C., Nordt, C., Falcato, L., \& Rössler, W. (2004). Factors influencing social distance toward people with mental illness. Community Mental Health Journal, 40(3), 265-274. doi: 10.1023/B:COMH.0000026999.87728.2d

Link, B. G., Phelan, J. C., Bresnahan, M., Stueve, A., \& Pescosolido, B. A. (1999). Public conceptions of mental illness: Labels, causes, dangerousness, and social distance. American Journal of Public Mental Health, 89(9), 1328-1333.

Mak, H. W., \& Davis, J. M. (2013). The application of the theory of planned behavior to help-seeking intention in a Chinese society. Social Psychiatry and Psychiatric Epidemiology, 1-15. doi: 10. 1007/s00127-013-0792-x

Marastuti, A. (2014). Hubungan antara mental health literacy dengan perilaku remaja dalam mencari bantuan tenaga kesehatan mental profesional: Studi remaja $S M P$ dan SMU di DIY. Laporan hibah tidak dipublikasikan, Fakultas Psikologi Universitas Gadjah Mada, Yogyakarta.

Mason, R. J., Hart, L. M., Rossetto, A., \& Jorm, A. F. (2015). Quality and predictors of adolescents' first aid intentions and actions towards a peer with a mental health problem. Psychiatry Research, 228(1), 31-38. doi: 10.1016/j.psychres.2015.03.036

McBain, R., Salhi, C., Morris, J. E., Salomon, J. A., \& Betancourt, T. S. (2012). Disease burden and mental health system capacity: WHO Atlas study of 117 low- and middle-income countries. British Journal of Psychiatry, 201(6), 444-450. doi: 10.1192/ bjp.bp. 112.112318

Mehta, N., \& Thornicroft, G. (2014). Stigma, Discrimination, and
Promoting Human Rights. Dalam V. Patel, H. Minas, A. Cohen, \& M. J. Prince (Eds.), Global mental health: Principles and practice (hlm. 401-424). New York: Oxford University Press.

Mendoza, H., Masuda, A., \& Swartout, K. M. (2015). Mental health stigma and self-concealment as predictors of helpseeking attitudes among Latina/o college students in the United States. International Journal for the Advancement of Counselling, 37(3), 207-222. doi: 10. 1007/s10447-015-9237-4

O'Connor, M., \& Casey, L. (2015). The mental health literacy scale (MHLS): A new scale-based measure of mental health literacy. Psychiatry Research, 229(1-2), 511-516. doi: 10.1016/ j. psychres.2015.05.064

O'Connor, M., Casey, L., \& Clough, B. (2014). Measuring mental health literacy - a review of scale-based measures. Journal of Mental Health, 23(4), 197-204. doi: 10.3109/ 09638237. 2014.910646

Ojeda, V. D., \& Bergstresser, S. M. (2008). Gender, race-ethnicity, and psychosocial barriers to mental health care: An examination of perceptions and attitudes among adults reporting unmet need. Journal of Health and Social Behavior, 49(3), 317-334. doi: 10.1177/ 002214650804900306

Putri, A. S., Martiningtyas, M. A. D., Sagala, A .E. S. B., Erawan, G. N., Yana, I. P. A., Martiningtyas, D., Matulu, S.,...\& Subandi. (2013). Era baru kesehatan mental Indonesia: Sebuah kisah dari desa siaga sehat jiwa (DSSJ). Jurnal Psikologi, 40(2), 169180.

Reynders, A., Kerkhof, A. J. F. M., Molenberghs, G., \& Van Audenhove, C. (2015). Help-seeking, stigma and 
attitudes of people with and without a suicidal past. A comparison between a low and a high suicide rate country. Journal of Affective Disorders, 178, 5-11. doi: 10.1016/j.jad.2015.02.013

Rickwood, D., Deane, F. P., Wilson, C. J., \& Ciarrochi, J. (2005). Young people's help-seeking for mental health problems. Australian E-Journal for the Advancement of Mental Health, 4(3), 218-251. doi: 10.5172/jamh.4.3.218

Rickwood, D., Thomas, K., \& Bradford, S. (2012, August). Help-seeking measures in mental health: A rapid review. Diunduh dari https://www. saxinstitute.org.au/wp-content/ uploads/02_Help-seeking-measuresin-mental-health.pdf

Salim, A. Z. (2014). Keterkaitan antara stigma, keyakinan, dan niat keluarga dalam mencari pertolongan untuk anggota keluarga yang rentan mengalami gangguan mental di Yogyakarta. (Disertasi tidak Dipublikasikan). Fakultas Psikologi Universitas Gadjah Mada, Yogyakarta.

Subandi. (2012). Agama dalam Perjalanan Gangguan Mental Psikotik dalam Konteks Budaya Jawa. Jurnal Psikologi, 39(2), 167-179.

Subandi \& Utami, M. S. (1996). Pola perilaku mencari bantuan pada keluarga pasien gangguan jiwa. Jurnal Psikologi, 2, 1-10.

Sun, K. S., Lam, T. P., Lam, K. F., Lo, T. L., Chao, D. V. K., \& Lam, E. W. W. (2016). Barriers of Chinese primary care attenders to seeking help for psychological distress in Hong Kong. Journal of Affective Disorders, 196, 164170. doi: 10.1016/j.jad.2016.02.041

Taylor, S. M., \& Dear, M. J. (1981). Scaling community attitudes toward the mentally ill. Schizophrenia Bulletin, 7(2),
225-240. doi: 10.1093/schbul/7.2.225

Umubyeyi, A., Mogren, I., Ntaganira, J., \& Krantz, G. (2016). Help-seeking behaviours, barriers to care and selfefficacy for seeking mental health care: a population-based study in Rwanda. Social Psychiatry and Psychiatric Epidemiology, 51(1), 81-92. doi: 10.1007/ s00127-015-1130-2

Uwakwe, R., \& Otakpor, A. (2014). Public mental health: Using the mental health gap action program to put all hands to the pumps. Frontiers in Public Health, 2, 1-5. doi: 10.3389/fpubh.2014.00033

Wang, J., He, Y., Jiang, Q., Cai, J., Wang, W., Zeng, Q., ... Zhang, M. (2013). Mental health literacy among residents in Shanghai. Shanghai Archives of Psychiatry, 25(4), 224-235. doi: 10.3969/ j.issn.1002-0829.2013.04.004

Wilson, C. J., Bushnell, J. A., \& Caputi, P. (2011). Early access and help seeking: Practice implications and new initiatives. Early Intervention in Psychiatry, 5, 34-39. doi: 10.1111/j.17517893.2010.00238.x

Wong, Y. J., Tran, K. K., Kim, S-H., Kerne, V. V. H., \& Calfa, N. A. (2010). Asian American's lay beliefs about depression and professional helpseeking. Journal of Clinical Psychology, 66(3), 317-332.

World Health Organization. (2001). The world health report 2001 - mental health: New understanding, new hope. France: WHO Library Cataloguing-inPublication Data.

World Health Organization. (2012). Mental health atlas 2011. Geneva: WHO Library Cataloguing-in-Publication Data.

Wright, A., Jorm, A. F., \& Mackinnon, A. J. (2011). Labeling of mental disorders and stigma in young people. Social 


\section{LITERASI KESEHATAN MENTAL DAN SIKAP KOMUNITAS}

Science and Medicine, 73(4), 498-506. doi: 10.1016/j.socscimed.2011.06.015

Yap, M. B. H., \& Jorm, A. F. (2012). Young people's mental health first aid intentions and beliefs prospectively predict their actions: Findings from an Australian National Survey of Youth. Psychiatry Research, 196(2-3), 315-319. doi: 10.1016/j.psychres.2011.10.004 